Mert Karabey
Ankara University, karabeymert@yahoo.com, Ankara-Turkey

\begin{tabular}{l}
\begin{tabular}{l|l|l} 
DOI & http: $/ / \mathrm{dx} . \mathrm{doi}$. org/10.12739/NWSA.2018.13.4.D0218 \\
\hline ORCID ID & $0000-0002-5388-8619$ \\
\hline CORRESPONDING AUTHOR & Mert Karabey
\end{tabular} \\
\hline
\end{tabular}

\title{
12 TON SISTEMININ YARATICISI VE ÖĞRETMEN OLARAK ARNOLD SCHOENBERG
}

Öz

Arnold Schoenberg herhangi bir konservatuar ya da kurumda akademik bir müzik eğitimi almamış ve kendi kendini yetiştirmiştir. Bununla birlikte, müzik tarihinde önemli bir devrim yaratan 12 ton sistemini ortaya koymuş, hayatının büyük bölümünde özel dersler vermiş ve çeşitli akademilerde öğretmenlik yapmıştır. Yetiştirdiği çok sayıda besteci arasında yalnızca Anton Webern ve Alban Berg'i anmak bile, onun eğitimci olarak başarısını özetleyebilir. Bu makalede kendi kendini yetiştirmiş bir besteci olan Arnold Schoenberg'in, 12 ton sistemini nasıl ortaya koyduğu ve bunun yanı sıra eğitimciliği incelenmiştir.

Anahtar Kelimeler: Schoenberg, 12 Ton Sistemi, Dizi, Öğretmen Olarak Schoenberg, Besteci Olarak Schoenberg

\section{ARNOLD SCHOENBERG AS CREATOR OF THE 12 TONE SYSTEM AND AS A TEACHER}

\section{ABSTRACT}

Arnold Schoenberg did not have an academic music education at a conservatory or an institution; he was self-taught. However, he established the 12 tone system which brought an important revolution to the history of music. In most of his life, he gave private lessons and taught at several academies. Among his many students, mentioning Anton Webern and Alban Berg would be enough to indicate his success as an educator. In this article, it is analyzed, as a self-taught composer how Arnold Schoenberg invented the 12 tone system along with being an educator.

Keywords: Schoenberg, 12 Tone System, Serie, Schoenberg as a Teacher, Schoenberg as a Composer 


\section{GİRIŞ (INTRODUCTION)}

Arnold Schoenberg, yirminci yüzyılın, üstünde en çok tartışılan ve yazılan bestecilerinden biridir. Öncü bir atonalist ve 12 ton sisteminin bulucusu olarak, hakkında en ateşli övgüden, en abartılı saldırıya kadar uzanan sayısız fikir öne sürülmüştür. Birinci Dünya Savaşı yılları ve sonrasında geliştirdiği 12 ton sistemi müzik tarihinde büyük bir dönüm noktası olmuş, yalnızca Schoenberg'in öğrencilerine değil, ileri kuşaklardan çok sayıda besteciye de ilham kaynağı olmuştur. Schoenberg sistemini, öğrencilerine dayatmamıştır. Her öğrencisi 12 ton sistemini kendi yaratıcılığı içinde yeniden yorumlamıştır. Bilindiği gibi schoenberg, hayatının büyük kısmında geçimini, özel dersler vererek ya da çeşitli akademilerde görev alarak, öğretmen olarak sağlamış, çok sayıda öğrenci yetiştirmiş ve geniş anlamıyla- müzik teorisi alanında da eserler vermiştir. Bu makalede Schoenberg'in 12 ton sistemini ne şekilde ortaya koyduğu, başlıca öğrencileri olan Berg ve Webern'in bu teknikten nasıl yararlandıkları ve bunun yanı sıra, daha az üstünde durulmuş bir yönü, öğretmenliği ele alınmıştır.

\section{2. ÇALIŞMANIN ÖNEMI (RESEARCH SIGNIFICANCE)}

Schoenberg hakkında çok sayıda kitap ve makale bulunmakla birlikte, öğretmenliği hakkındaki kaynaklar oldukça sınırlıdır. 12 ton sistemi/tekniği teorik kitaplarda yer almakla birlikte, öğrencilerinin bu teknikten yararlanırken ortaya koydukları dilin Schoenberg ile kıyaslanması da bestecilik eğitimi açısından dikkate değerdir. Schoenberg'in 12 ton sistemi ve öğretmenliğini birlikte ele alan bu çalışmanın, besteci adaylarına, teorisyen ve kompozisyon eğitimcilerine yol gösterici olacağı düşünülmektedir.

\section{ANAKONU (SUBJECT)}

\subsection{Biyografi (Biography)}

Arnold (Franz Walter) Schönberg (ya da Amerika'ya gö̧ ettikten sonra benimsediği yazılışla Schoenberg), 13 Eylül 1874'te Viyana'da doğdu. Ailesi Viyana'ya, günümüzde Slovakya'nın başkenti olan Bratislava'dan (o zamanlar daha yaygın olan Almanca adıyla Pressburg) gelmişti. Adı geçen kent o tarihlerde Avusturya-Macaristan Imparatorluğu'nun Macaristan tacına bağlıydı. Dolayısıyla Schoenberg Macaristan vatandaşlığını almıştı. Çekoslovakya'nın kuruluşuyla ise Çekoslovakya vatandaşı olmuş, 1941'de ise Amerika Birleşik Devletleri uyruğuna geçmiştir. Schoenberg'in ailesi Yahudi'ydi ve Viyana küçükburjuvazisinin en alt tabakasından geliyordu. Şirle ilgilenen ve Schoenberg'e Fransızca öğreten dayısı Franz Nachod sayılmazsa, Schoenberg'in çocukluğu ve ilk gençliği entellektüel bir çevrede geçmedi. Ailesinin müziğe karşı özel bir ilgisi de yoktu. Sekiz yaşında keman dersleri almaya başladıysa da akademik bir müzik öğrenimi görmedi. Babasının ölümünün ardından 1890'dan başlayarak, beş yıl özel bir bankada kâtip olarak çalışmak zorunda kaldı. Bir yandan da Alexander von Zemlinsky'nin yönettiği amatör Polyhymnia Orkestrası'nda viyolonsel çaldı. Armoni, kontrpuan ve kompozisyon dersleri aldığı Zemlinsky ile yakın dost oldu.

İzleyici önünde seslendirilen ilk yapıtı 1897 sonbaharında yazdığı Re Majör Yaylı Çalgılar Dörtlüsü idi (Neighbour, 2001:587). Brahms etkileri taşıyan bu romantik yapıt, Zemlinsky'nin önerisiyle 1897-1898 sezonunda seslendirildiğinde çok olumlu karşılandı. Schoenberg daha sonraki erken dönem yapıtlarında tonaliteyi Wagneryen kromatizmi daha da yoğunlaştırarak zorlamakla beraber, 1908'e kadar yazdıklarıyla hâlâ tonaliteden bütünüyle kopmuş değildir. Ama dönemin tutucu Viyana dinleyicisinin çözümsüz dissonanslara tahammülü yoktu. 
1899 tarihli Verklärte Nacht (Aydınlanan Gece) Aralık 1900'deki ilk seslendirilişinde protestolarla karşılandı. Ve bundan sonra, Schoenberg'in kendi deyişiyle, skandal hiç bitmedi (Neighbour, 1988: 3). 1898 yılında vaftiz olarak Protestanlığı benimsemiş olan Schoenberg, 1901 Ekim'inde Zemlinsky'nin kız kardeşi Mathilde ile evlendi (bu evlilikten iki çocuğu oldu). Viyana'da geçinmekte zorluk çekince yıl sonunda Berlin'e taşındı ve yaklaşık bir yıl kadar Überbrettl adlı bir kabare tiyatrosunda çalıştı. Berlin'de Richard Strauss'tan destek gördü. Onun önerisiyle Liszt stipendum adlı bursu aldı ve Stern Konservatuarı'nda kompozisyon dersleri verdi. 1903'te Viyana'ya döndü. Viyana'da öğretmenlik yaparak geçimini kazanırken, müziğinde daha da cesur denemelere girişti. Ona sadık bir öğrenci çevresi oluşurken, Viyana'ya dönüşünde tanıştığı Gustav Mahler tarafından desteklendi. Viyana'ya dönüşünden (1911 ile 1915 arasında yine Berlin'de yaşamıştır) Birinci Dünya Savaşı'na kadar yazdığı başlıca yapıtları arasında, senfonik şiiri Pelléas ve Mélisande (1903), ilk iki yaylı çalgılar dörtlüsü (1905 ve 1908), Die Glückliche Hand (Mutlu El;1908-1913) adlı müzikli dramı, Erwartung (Bekleyiş;1909) adlı monodramı, 5 Orkestra Parçası (1909) ve Pierrot Lunaire (1912) sayılabilir. Bu yapıtlarından sonuncusu özellikle önemlidir ve Schoenberg'in ekspresyonist (teknik olarak serbest atonal) döneminin başyapıtı olarak kabul edilebilir. Berlin'de yazdığı bu eserde Schoenberg, daha sonraları Luciano Berio'dan Harrison Birthwistle'a birçok besteciyi etkileyecek olan sprechstimme (konuşmaşarkı) tekniğini geliştirmiştir.

Birinci Dünya Savaşı yıllarında birkaç sefer askere alınan Schoenberg'in müziksel yaratıcılığının, 1920'ye kadar çok az ürün verdiğini görüyoruz. Ama yine bu ylllar, Schoenberg'in tonalite ve atonalitenin (Schoenberg benimsemediği atonal terimi yerine pantonal kelimesini öneriyordu) imkânları üstüne düşündüğü, zihinsel açıdan verimli yıllar olmuştur. 1920-1923 yılları arasında ise 12 ton (12 nota) sistemi üstüne çalışmalarını sonuçlandırmıştır. Bu sistemle atonal müzik belli bir disipline kavuşuyordu. Schoenberg'in bu tekniğe ilk olarak yer veren yapıtı ise 5 Piyano Parçası op.23 (1920-1923) idi. Bundan sonraki yapıtlarında birkaç tonal eser vermekle beraber12 ton tekniğini kullandı.

Aynı yıllarda Josef Matthias Hauer (1883-1959) adlı Avusturyalı bir besteci de aynı sistem üzerinde çalışmaktaydı. Metodu trope adını verdiği dizilere dayanıyordu. Bu dizileri kullandığı metodunda 479.001.000 olası kombinasyon hesaplamıştı (Lichtenfeld, 2001:134). Schoenberg kendi sistemini bağımsız olarak geliştirmekle beraber, Hauer'in sistemiyle de ilgilenmiş, 1918-1925 tarihleri arasında temas halinde olmuşlardı. Hauer sistemini müzikal anlamda var etmekte Schoenberg'le aynı yaratıcılığa sahip olmadığından izleyicisi çıkmamış ve bir süre sonra unutulmuştur.

Schoenberg 1923 Ekim'inde karısı Mathilde Schoenberg'i kaybetti. Ertesi yıl Schoenberg, öğrencisi olan, kemancl Rudolf Kolisch'in kız kardeşi Gertrud Kolisch ile evlendi (bu evlilikten üç çocuğu oldu) . İzleyen ylllar Schoenberg'in ünü arttı. 1925'te Berlin'deki Prusya Sanatlar Akademisi kompozisyon üst sınıfı öğretmenliğine ve yöneticiliğine getirildi. Yavaş yavaş uluslararası bir ün kazanmaya başladı. Akademideki görevi, 1933 yılında Hitler'in iktidara gelmesiyle son buldu. Yahudi kökenli olan Schoenberg, Almanya'dan ayrılarak önce Paris'e gitti ve orada Yahudi inancına resmen geri döndü. Ardından Amerika'ya göç etti. Önce Boston'daki Malkin Konservatuarı'nda ders verdi. Sağlık sebepleriyle California'ya taşındı. Önce Güney California Üniversitesi, ardından Los Angeles'taki Calfornia Üniversitesi'nde ders verdi. Keman Konçertosu (1934-1936), 
2. Oda Senfonisi (1939-1906'da başlanmış), Ode to Napoleon (1942), Piyano Konçertosu (1942), Yaylı Çalgılar Triosu op.45 (1946) Amerika'da yazdığı yapıtlar arasında sayılabilir. 1944'te sağlığının kötüleşmesi üzerine üniversitedeki görevinden emekliye ayrıldı, ama ekonomik sebeplerle özel dersler vermeyi sürdürdü. 1946'da Chicago Üniversitesi'nde bir dönem ders verebilecek kadar iyileşti. Son yıllarında dinsel ilhama dayanan koral yapıtlar üstünde çalıştı. Sağlık sıkıntıları içinde geçen bu son yılların ardından, 13 Temmuz 1951'de Los Angeles'ta öldü.

Schoenberg'in müzik teorisi alanındaki didaktik kitapları şunlardır: Harmonielehre (Armoni Kuramı, 1911), Models for Beginners in Composition (Kompozisyona Yeni Başlayanlar için Modeller, 1942), Structural Functions of Harmony (Armonin Yapısal İşlevleri, 1954), Preliminary Exercises in Counterpoint (Kontrpuan Üzerine Ön Alıştırmalar, 1963), Fundamentals of Musical Composition (Müzikal Kompozisyonun Esasları, 1967).

\section{2. Öğretmen Olarak Schoenberg (Schoenberg as a Teacher)}

\subsubsection{Kendi Kendinin Öğretmeni (Otodidakt) (Self-Teacher)}

Belirtildiği gibi Schoenberg düzenli bir müzik eğitimi görmedi. Hatta hiç müzik eğitimi görmedi de denebilir. Schoenberg geniş bilgisini neredeyse tamamı ile kendi kendini eğiterek sağlamıştır. Bilgisini düzenli bir eğitimden çok, araştırıcı zekâsına, merakına ve çevresindeki müzisyen dostlarına borçludur. Sekiz yaşında keman dersleri alan Schoenberg'in, kompozisyon alanındaki ilk modelleri kuzeniyle birlikte çaldığı Pleyel ve Viotti'nin keman düoları olmuştur. Babasının ölümü üstüne bankada çalışmak zorunda kaldığı yıllarda iki arkadaşı ona müzik konusunda bilgisini geliştirmesinde katkıda bulunmuşlardır. Bu iki arkadaştan biri olan oskar Adler (ki kendisi iyi bir kemanclydı ve ileriki yıllarda felsefe alanında etkinlik gösterecekti), ona kulak eğitimi ve armoniye başlangıç konularında yardım etmiştir. Diğer arkadaşı David Josef Bach ise onu artistik düşüncelerini yüksek tutması konusunda cesaretlendirmiştir. Üç arkadaş birlikte oda müziği repertuarını tanımak için amatör bir ensemble kurmuşlar, akşamları birlikte müzik yapmışlardır. Bir viyolonsele ihtiyaç duyduklarında, Schoenberg viyolaya zither teli gerip viyolonsel gibi akord etmiş, ardından bir viyolonsel edindiklerinde de Schoenberg aleti bir süre keman parmaklarıyla çalmaya devam etmiştir.

Derken Adler, Viyana Filarmoni'de çalan bir viyolonselciden doğrusunu öğrenip, doğru parmakları Schoenberg'e göstermiştir. Bir yandan da Schoenberg müzik formları konusunda ansiklopedilerden okuyarak bilgi edinmeye çalışmıştır. Arkadaşı Bach'ın aktardığına göre genelde konserlere gitmeye parası olmayan Schoenberg, cafélerin önünde yürüyüş yaparak bedava müzik dinlemeye çalışırdı (Stuckenchmidt, 1977:22). Hâlâ bankada çalışmakta olduğu yıllarda, viyolonsel çaldığı amatör Polyhmnia'nın şefi, besteci Alekander von Zemlinsky (1872-1942) onun tek kompozisyon hocası olmuştur. Her ne kadar Zemlinsky, daha sonra, alçak gönüllülükle yalnızca birbirlerine kompozisyonlarını gösterdiklerini söylediyse de Schoenberg'in bestecilik konusundaki kararlılığını arttırmıştır. Schoenberg'in bu ilk adımlarına özellikle değinilmesinin sebebi, onun bu elverişsiz koşullarda kendini eğitmesinin, bir yandan da ileride öğretmen olarak kullanacă̆ı metodları oluşturmasıdır. Onun için, genç bir bestecinin eğitiminde önemli olan verilen hazır bilgi değil, deneme yanılma yöntemiyle kendi dilini oluşturmasıdır. Bunda da temel kaynak, teorik kitaplardan çok, daha önceki usta bestecilerin eserleridir. 


\subsubsection{Viyana'daki Öğretmenliği ve Öğrencileri: Webern, Berg ve Diğerleri (Teacher and Students in Vienna: Webern, Berg and Others)}

Schoenberg ilk olarak, 1902 yllında, Richard Strauss'un önerisi üzerine görev aldığı Berlin'deki Stern Konservatuarı'nda öğretmenliğe başladı. Burada kısa bir süre kompozisyon dersleri verdi. 1903'te Viyana'ya dönen Schoenberg, 1904'te Dr. Eugenie Schwarzwald'ın yönetimindeki bir kız okulunun sınıflarında armoni ve kontrpuan dersleri vermeye başladı. Aynı kurumda Zemlinsky de form bilgisi ve orkestrasyon dersleri vermekteydi. Buradaki öğretmenliği Schoenberg'i hayâl kırıklığına uğrattı. Öğrencilerin çoğunu yetenekli bulmuyordu. Bir yıl kadar sonra burada ders vermeyi bıraktı; kompozisyona yetenekli bulduğu öğrencilere evinde özel ders vermeye devam etti. Burada tanıştığı iki genç onun en parlak öğrencileri oldular ve müzik tarihinde onun kadar önemli bir yer kazandılar: Anton von Webern ve Alban Berg. Böylelikle İkinci Viyana Okulu doğuyordu. Genç Anton von Webern (1883-1945), Viyana Üniversitesi'nde müzikoloji öğrenimi görmekteydi. Viyolonsel ve piyano da çalan Webern, kompozisyon dersleri almak için, önce Berlin'deki Stern Konservatuarı'nda ders veren Hans Pfitzner'le (1896-1849) görüşmeye gitti; ama Pfitzner'in Mahler'i eleştirmesi üstüne onunla kavga ederek Viyana'ya döndü ve kısa bir süre sonra da Schoenberg'in öğrencisi oldu. Schoenberg'le çalışmaları dört yıl kadar sürecekti. Bu süre zarfında genç Webern, çeşitli türlerde, teknik egzersizleri ve tamamlanmamış bölümleri de içeren yüz kadar parça yazdı. Schoenberg Webern'in özellikle vokal müzikteki doğuştan gelen yeteneğini kısa sürede fark etmişti. Çabasını daha çok onun çalgısal tekniğini geliştirmekte yoğunlaştırdı. Geleneksel formlarda çok sayıda deneme yazdırmakla beraber, Schoenberg için asıl önemli olan öğrencinin kendini ifade edecek dili geliştirmesiydi. 1912'de Berg'le birlikte editörlüğünü üstlendikleri Schoenberg'i tanıtan Der Lehrer (Öğretmen) adlı kitapta şöyle diyordu Webern:

"İnsanlar sanıyorlar ki Schoenberg kendi stilini öğretiyor ve öğrencilerini bunu benimsemeye zorluyor. Bu yanlış; Schoenberg hiçbir stili öğretmez ne eski ne de yeni hiçbir artistik kaynağı vaaz etmez. Schoenberg öğrencisinden her şeyden önce şunu talep eder: öğrencinin yazdıkları eski akademik formları doldurmak için yeni notalar yazmak olmamalıdır; kendini ifade etmek ihtiyacının sonucu olan bir başarı hedeflenmelidir. Dolayısıyla öğrenci daha ilk adımlarında yaratmak zorundadır." (Reich, 1981:27)

Aynı kitapta Schoenberg'in diğer bir öğrencisi, Karl Horowitz, Webern'i şu sözlerle doğruluyor:

"'Bundan bir şey öğrenmeye çalışma; daha ziyade Mozart, Beethoven ve Brahms'tan öğren! Belki, böylelikle, buradaki bazı değerli şeyler gözüne çarpacaktır.' Bu sözler Schoenberg'in 1. Yaylı Çalgılar Dörtlüsü'nün (op.7) bana ait olan kopyasının üstüne Arnold Schoenberg tarafından yazılmıştı. Bu sözlerin anlamını onunla geçen öğrencilik yıllarımda keşfettim." (Reich, 1981:27)

Webern'in Schoenberg'le olan çalışmaları onun opus numarası verdiği ilk yapıtıyla, Passacaglia op.1 (1908) sonlanmıştır. Bu yapıtla Webern henüz kendi sesini bulmuş değildir. Ama bu geç-romantik eğilimli yapıt, onun ulaştığı teknik düzeyi ve müzikal derinliği göstermesi açısından çarpıcıdır. Webern 1914 yılında Schoenberg'e yazdığı bir mektupta, ustasına olan bağlılığını şöyle dile getiriyor:

"Size söylemek isterim ki; o zamanların anısı (Schoenberg'le çalıştığı yılları kastederek) benim için ne kadar da güzel. İnanıyorum ki her bir sözünüzü, her bir dersinizi hatırlayabilirim. Hepsi, tüm söyledikleriniz, benim için ölçülemez bir değerde... 
Siz benim kalbimde en yüksek ideali oluşturdunuz; ki size olan sevgim sürekli daha fazla artıyor, size olan bağlılığım sürekli daha da güçleniyor." (Hayes, 1995:47)

Alban Berg (1885-1935) Webern ile yaklaşık olarak aynı zamanda Schoenberg'in öğrencisi oldu. Lise bitirme sınavlarını henüz vermiş, edebiyata düşkün on dokuz yaşında bir gençti ve geleceği konusunda kesin bir fikri yoktu. Schoenberg'in ders verdiğini belirten gazete ilanını gören Berg'in kardeşi Charly, Berg'in haberi olmaksızın bestelerini Schoenberg'e göndermiş, o da Berg'i görüşmek üzere davet etmişti. İlk yıl Berg'in maddi durumu iyi olmadığından ondan ücret almamıştı. Berg o zamana kadar romantik stilde şarkılar yazıyordu. Ayrıca Schoenberg'le tanıştığında müzik teorisi konusunda epeyce bilgi sahibi olan, müzikoloji eğitimli Webern'in aksine, bilgisi çok sınırlıydı. Schoenberg, Berg'in yeteneğini hemen fark etmiş ve 1911'de Berlin'e ikinci gidişine kadar ona ders vermeyi sürdürmüştür. Berg bu yedi yıl içinde büyük gelişme kaydetmiş, Piyano Sonatı op.1 (19071908), Dört Şarkı op.2 (1909-1910), Yaylı Sazlar Dörtlüsü op.3 (1910) gibi önemli gençlik yapıtlarını ustanın gözetiminde vermiştir. Schoenberg Berg'in tek öğretmeni olmuş, aynı zamanda Webern gibi, Berg de Schoenberg'i bir model, hatta ideal olarak benimsemiş, hatta onu on beş yaşında kaybettiği babasının yerine koymuştur.

Schoenberg, Webern ve Berg birlikte 2. Viyana Okulu olarak adlandırılmışlardır. Ama üçünün de stil özellikleri ve müziksel duyarlılıkları birbirlerinden oldukça farklıdır. Her üçü de dizisel (12 ton) teknikle yazmaya başladıklarında da bu fark azalacağına daha da belirginleşmiştir. Diziyi tematik olarak kullanan Schoenberg, tematik transformasyonu esas alır, düşünüş tarzı büyük ölçüde kontrpuantaldir, form anlayışı romantik geleneği sürdürür. Webern diziyi tematik bir malzeme olarak görmez, yazısı noktasaldır, klagenfarbenmelodie adı verilen teknikle seslerin tinisal özelliklerini araştırır, yapıtlarında kısalık ve yalınlık esastır, form anlayışı da gelenekten uzaklaşmıştır. Berg içlerinde en romantik eğilimli olanıdır, lirik çizgiler ve Keman Konçertosu'nda olduğu gibi tonal çağrışımlara açık bir dizi kullanımı söz konusudur; tekstür Schoenberg ve Webern'den çok daha yoğundur. Schoenberg'in, müzik tarihinde Webern ve Berg kadar önemli bir yer tutmamalarına karşın, yine de değerli besteciler olan diğer Viyana dönemi öğrencileri arasında şu isimler sayılabilir:

1921'de Schoenberg hakkında kitap uzunluğunda ilk çalışmayı yazan, Bizans müziği uzmanı bir müzikolog olmanın yanı sıra, yedi opera, dokuz senfoni besteleyen Egon Wellesz (1885-1974), daha çok müzikolog ve müzik yayımcısı olarak etkinlik gösteren Erwin Stein (1885-1958), ayni zamanda parlak bir piyanist olan Eduard Steuermann (1892-1964), ve Auschwitz'de ölen Der Kaiser von Atlantis operasının bestecisi Bohemyall Viktor Ullmann (1898-1944).

\subsubsection{Schoenberg'in Berlin ve Amerika Ylllarl (1925-1951) (Schoenberg's Berlin and the United States (1925-1951))}

Schoenberg'e 1925 yllında Berlin'deki Prusya Sanatlar Akademisi'nde kompozisyon üst sınıf öğretmenliği teklif edildi. Teklifi kabul eden Schoenberg, eylülde kontrat imzalayıp, Ocak 1926'da son kez olarak Viyana'dan Berlin'e taşındı. Roberto Gerhard (18961970) ve Winfried Zillig (1905-1963) gibi bazı öğrencileri de onu izlediler. Schoenberg'in akademideki görevi idari konuları da kapsıyordu ve derslerinin program ve içeriği de ona bırakılmıştı. Yılda ortalama altı ay ders vermek zorunda olduğundan, beste yapmaya da oldukça vakti kalıyordu. Schoenberg yedi yıl süren bu görevi sırasında maddi olarak hayatının en rahat dönemini geçirmiş, ayrıca 
$\overline{\text { besteci olarak da verimliliği en azından nicelik bakımından artmıştır. }}$ Ama öğrencileri tarafından neredeyse peygamber olarak görüldüğü Viyana'ya kıyasla, öğretmen olarak etkisinin azaldığını söyleyebiliriz. Buradaki öğrencilerinin hiçbiri de bir Berg ya da Webern düzeyine çıkamamışlardır.

1933'te Adolf Hitler'in iktidara gelmesiyle, Yahudi kökenli olan Schoenberg'in akademideki görevi de son bulmuştur. Önce Fransa'ya geçen Schoenberg Amerika'dan gelen bir teklifi kabul ederek, 1933 Ekim'inde Amerika'ya göç etmiştir. Hayatının geri kalan kısmında Avrupa'yı bir daha göremeyecektir.

Schoenberg'in kabul ettiği teklif, Boston'da kendi adını taşıyan bir konservatuar kurmuş olan viyolonselci Joseph Malkin'den gelmiştir. Schoenberg bu okulda kompozisyon dersleri verecektir. Seçkin bir öğretim kadrosuna sahip olmakla beraber küçük bir okuldu Malkin Konservatuarı ve bir orkestrası olmaması da Schoenberg'i hayâl kırıklığına uğratmıştı. Başlangıçta Boston'da tek bir kompozisyon öğrencisi olmuştur; kendisiyle çalışmak için burs kazanan Lois Lautner. Lautner'den öğrendiğimize göre Schoenberg ilk aylarda yetersiz İngilizcesi yüzünden sıkıntı çekmiştir. Bir sonraki akademik dönemde üç öğrenci daha katılmıştır kompozisyon sınıfına. Bunlardan biri olan Lowndes Maury, Schoenberg'in derslerinde 12 ton sistemini öğretmediğini, öğrencilerine serial müzik yazmadan önce geleneksel formlarda ustalaşmaları gerektiğini belirttiğini söylemiştir (Stuckenschmidt, 1977:376).

Schoenberg, Malkin'e bağlı olarak New York'ta da ders vermek durumundaydı. Buradaki dersleri Ansonia otelinde veriyordu. Ama Boston'dan New York'a yaptığı yolculuklar onu çok yorduğundan, Malkin bir süre sonra New York'taki öğrencileri Boston'a getirtmeye başlamıştır.

New England'da, uzun süreden beri çektiği astım hastalığı daha da kötüleşen Schoenberg, ertesi yıl, kuru ve ılık havasından dolayı California'ya yerleşti. Burada önce Güney California üniversitesinde ders verdi, 1936 yılında da Los Angeles'taki California Üniversitesi'nde profesör olarak çalışmaya başladı. Buradaki öğrencilerinden biri de deneysel müziğiyle tanınan John Cage'tir (1912-1992).

\subsection{Schoenbeg, Webern Ve Berg'te 12 Ton Sisteminin Kullanımı (Use of the 12 Tons System in Schoenbeg, Webern and Berg)}

Schoenberg'in 12 ton sistemi şu şekilde özetlenebilir: Tampere sitemdeki on iki nota, bestecinin seçimi doğrultusunda, birbiri ardına, belli bir hiyerarşiye yer vermeksizin duyurulur. Bestecinin oluşturduğu orijinal dizinin (original), çevrimi (inversion), sondanbaşası (retrograde), çevrimin sondan-başası (retrograde-inversion) ve bunların diğer on bir perdeye transpoze edilmesi yoluyla, besteci kırk sekiz dizilik geniş bir imkâna ulaşır. Düşey ve dikey kullanım olasılıkları arttırır. Schoenberg 1936 tarihli 4. Yaylı Kuartet'i bestecinin 12 ton sistemini kullanışına iyi bir örnek teşkil eder. Dizinin (serinin) dört formu aşă̆ıdaki gibidir: 

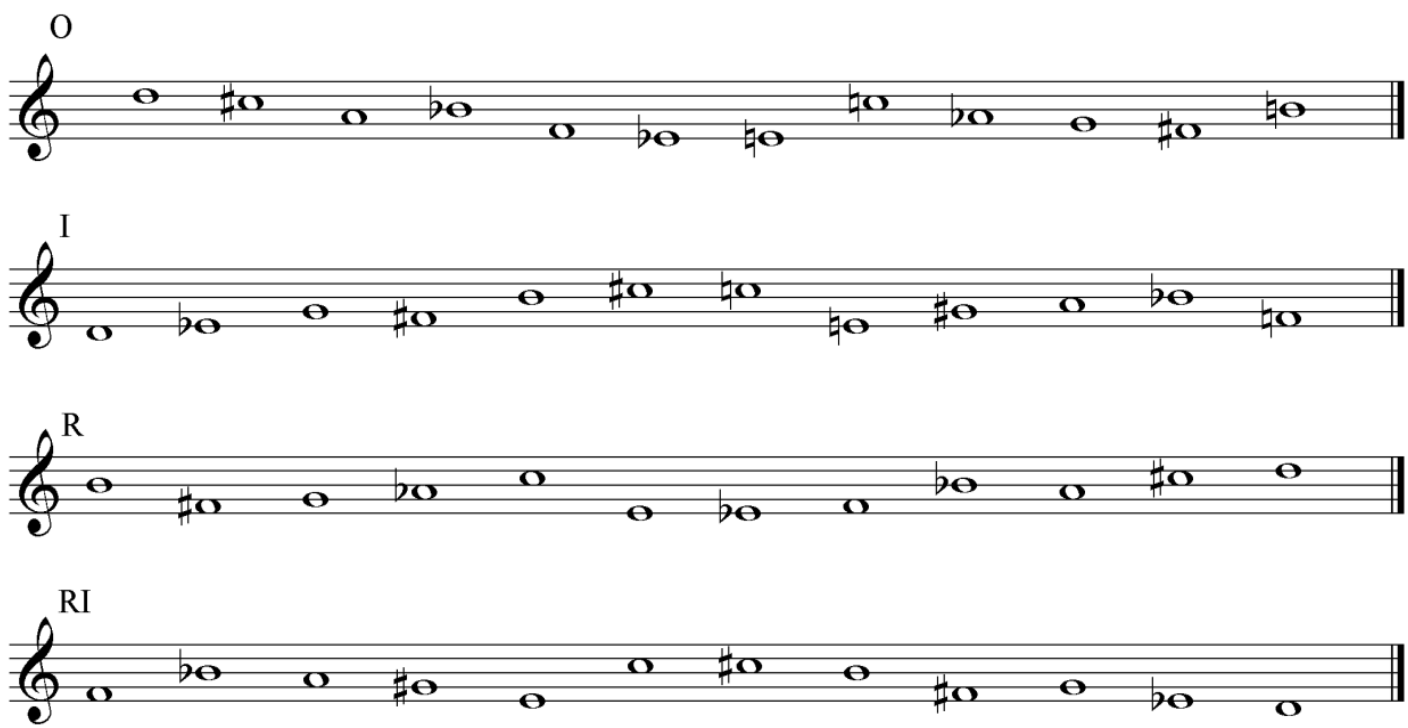

Örnek 1. Schoenberg'in 4. Kuarteti'nde kullanılan dizinin formları (Example 1. The forms of the series used in Schoenberg's 4th Quartet)

Eserin girişine baktığımızda Schoenberg'in birinci kemanda dizinin orijinal formunu tema olarak kullandığını görüyoruz (Schoenberg, 1939:1).
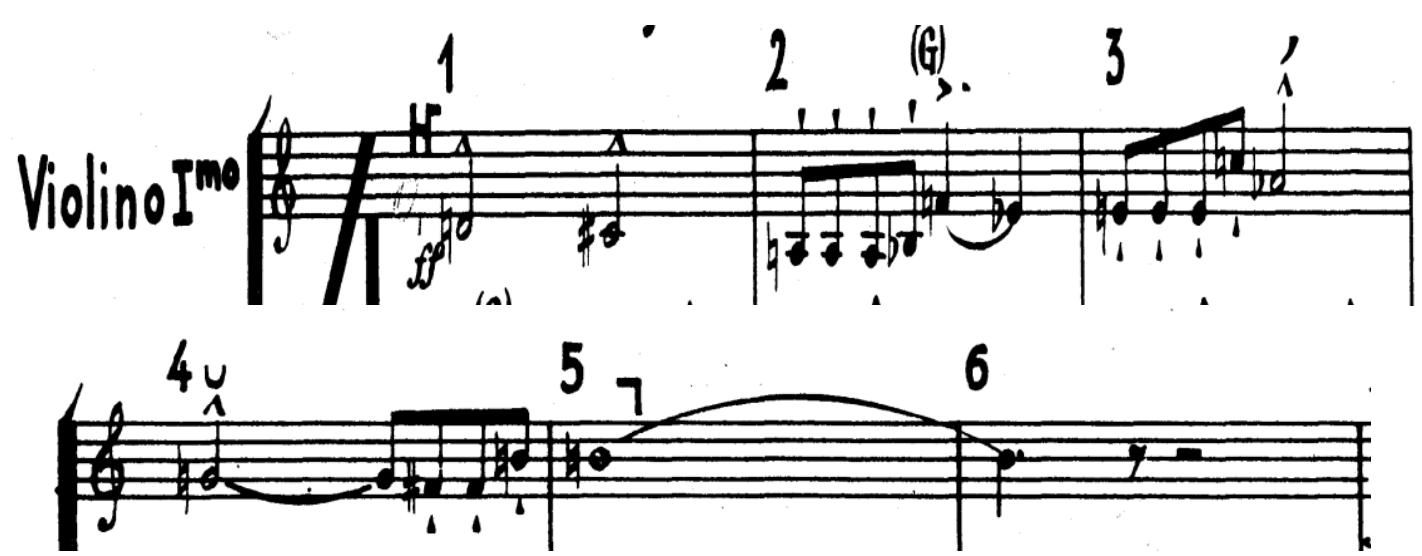

Örnek 2. Birinci bölümün A teması

(Example 2. Theme A of the first movment)

Eser boyunca bu tema farklı şekillerde karşımıza çıkar. Viyolonselde çevrimin (inversion) dördüncü transpozisyonu (Schoenberg, 1939:10).

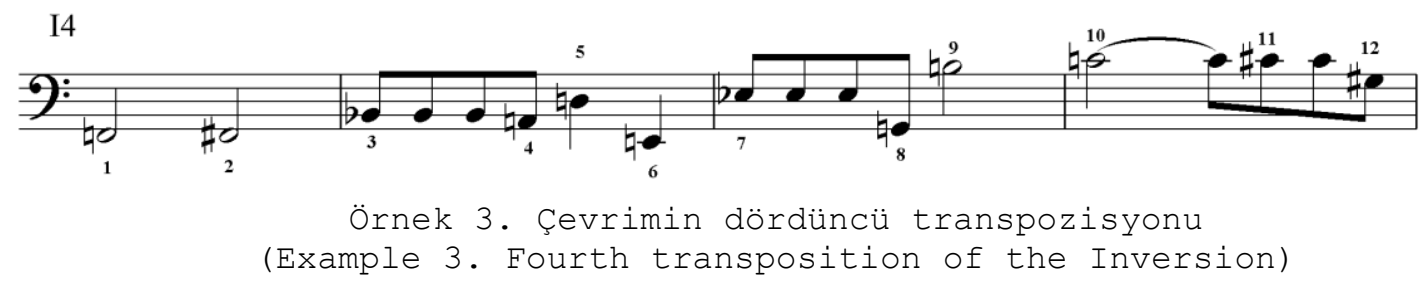




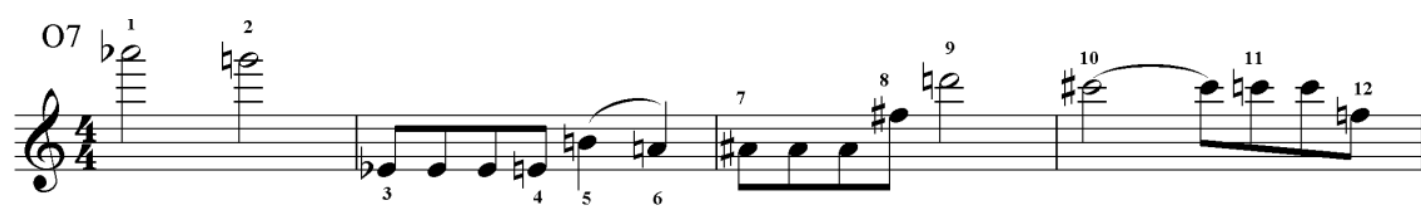

Örnek 4. Orijinal dizinin yedinci transpozisyonu

(Example 4. Seventh transpositon of the Original serie)

Tüm bu örneklerde temanın melodik ve ritmik karakterinin korunduğunu görüyoruz. Birinci bölümün ilk bölmesine dikkatli bir bakış, Schoenberg'in kuarteti melodik, armonik ve tekstürel olarak ele alışı hakkında iyi bir fikir verir (Schoenberg, 1939:1).
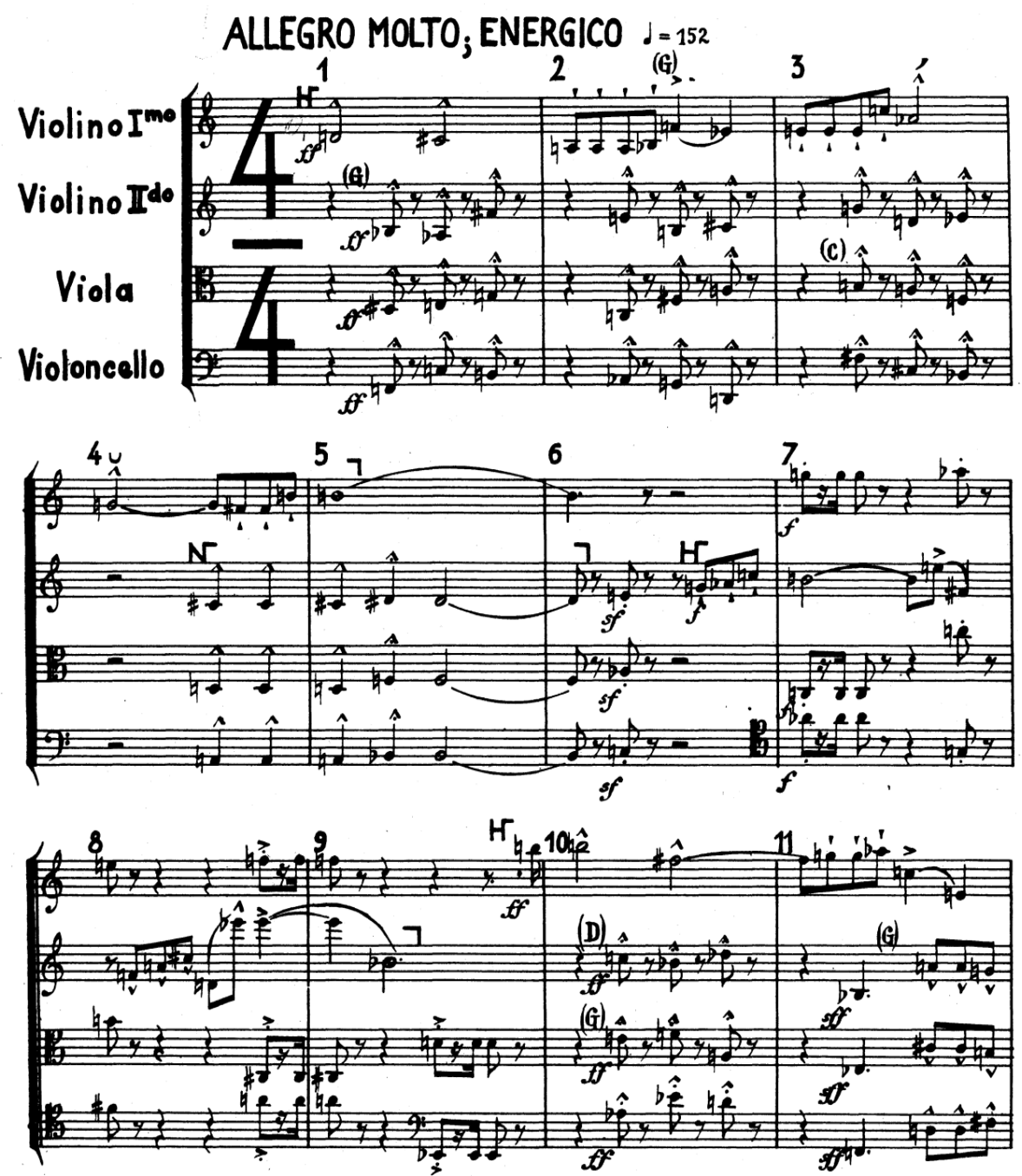

Örnek 5. Dördüncü Kuartet'in ilk 11 ölçüsü

(Example 5. First 11 bars of the 4 th Quartet)

Birinci keman temayı direkt bir biçimde duyurmaktadır. Diğer enstrümanlar akorlarla eşlik etmektedir. Hem melodide hem de eşlik eden akorlarda yukarıda verilmiş olan dizinin orijinal formu kullanılmakla birlikte, eserin tekstürel yapısının on dokuzuncu yüzyıl oda müziği geleneğinden kopmamış olduğunu görüyoruz. Schoenberg'in stilinin köklerinin Wagner ve Brahms'a dayandığı görüşü (Lester, 
1989:191) bestecinin olgunluk dönemine ait bu eserde bile haklılık kazanmaktadır. Schoenberg'in başta gelen öğrencilerinden Anton Webern'in op.28 Yaylı Kuartet'indeki dizi/seri kullanımı incelendiğinde, Schoenberg'in 4. Yaylı Kuartet'inden ne kadar farklı olduğu görülür. Webern'in orijinal serisi aşağıdaki gibidir.

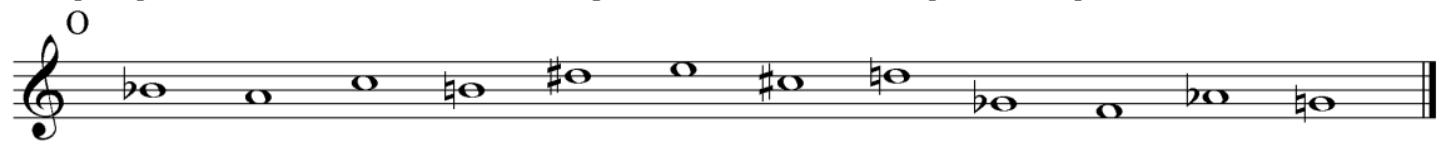

Örnek 6. Webern'in op.28 Yaylı Kuarteti'nin orijinal serisi

(Example 6. The Original serie in Webern's String Quartet op.28)

Fakat Webern diziyi Schoenberg gibi tematik olarak kullanmaz. Orijinal serinin enstrümanlara noktasal bir biçimde dağıtıldığı görülür. Bu noktsallık Webern'in müziğinin karakteristik özelliklerinden biridir (Webern, 1939:1).
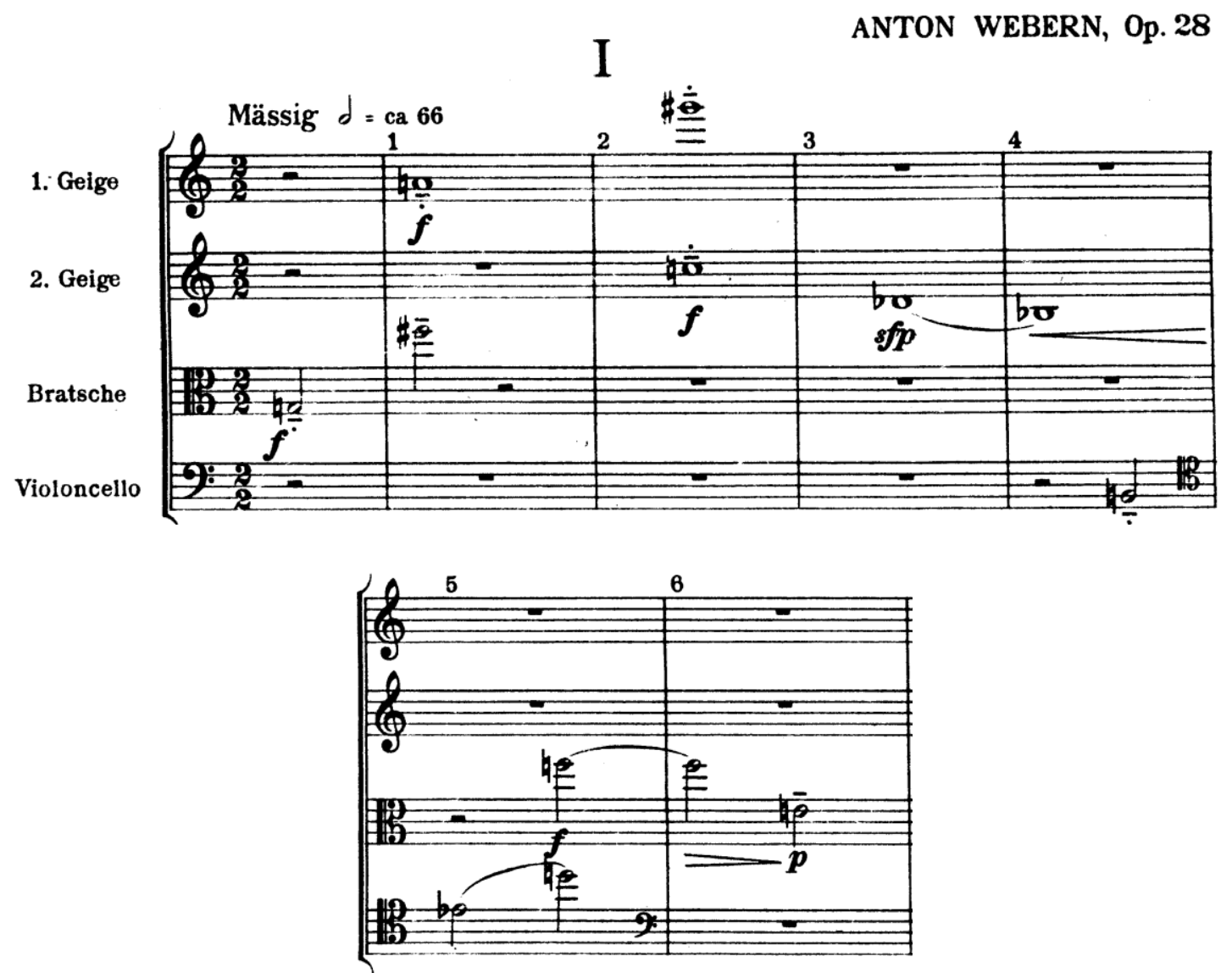

Örnek 7. op.28'in ilk 6 ölçüsünde orijinal seri kullanımı

(Example 7. The usage of the original serie in the first 6 bars of op. 28)

Schoenberg'in kuartetindeki jestler, cümleleme ve formlar, geçromantik müziğe ait özellikler gösterirken, Webern'in müziği yeni bir yöne doğru gitmektedir (Lester, 1989:196). Varyasyon gibi eski bir formu kullanmakla birlikte, Webern'in kuartetinin ilk bölümü, tekstürel ve tınısal açıdan çok daha yenilikçidir. Notalardan çok eslere yer veren kesintili yazı, geniş aralıklı dissonant atlamalar, açılı çizgiler, notaların noktasal (pointillistic) dağılımı Webern'in müziğinin tipik özellikleridir (Dallin, 1974:206). Dizinin kullanımı 
Schoenberg'teki gibi tematik ve çizgisel değildir. Webern için seslerin tınları da perde ve ritim kadar önemlidir. Dizinin bir enstrümandansa, farklı enstrümanlara dağıtılarak tınının bu şekilde ön plana çıkarılmasına Almanca Klangfarbenmelodie (ses rengi melodisi) adl verilir (Burkholder vd., 2006:828). Terim Schoenberg'e ait olmakla birlikte, kullanım nerdeyse Webern'le özdeşleşmiştir. Weber'in op.28'indeki diziye dikkatli baktığımızda göze çarpan bir başka ayrıntı, içerdiği simetridir. Dizinin ikinci yarısındaki heksakord (6 nota), birinci yarısındaki heksakordun sondan-başasının çevrimidir (RI). Bu da Webern'in dizileri oluştururken matematiksel simetrilere duyduğu ilginin bir örneğini teşkil eder. Webern'in stilinin bir başka özelliği de formlardaki kısalıktır. Bu durumu op.28'de de gözlemlemek mümkündür. Schoenberg'in 4. Yaylı Kuartet'inin çalınması yarım saati geçerken, Webern'in kuarteti sekiz dakikayı bulmaz. Webern'in müziğinde kontrpuantal prosedürler ve 12 ton sistemine katı bağlılıkla belirginleşen bir ekonomiklik söz konusudur. Yaşamı sırasında çok az takdir gören ve müziği yaygınlık kazanmayan Webern, II. Dünya Savaşı sonrasında, teorisyen ve besteciler tarafından gittikçe daha fazla önemsenmiştir (Burkholder vd., 2006:829). Webern'in 12 ton sistemini kullanışındaki yenilikçi tavrı, kompozisyona sistematik yaklaşımı ve eserlerinin tekstürel yapısındaki özgünlük, onu savaş sonrası kuşağın örnek aldığı besteci durumuna getirmiştir. Alban Berg'in 12 ton sistemine yaklaşımı, arkadaşı Webern'den oldukça farklıdır. 12 ton tekniğinin tonal çă̆ırışımlarla nasıl kullanılabileceğine çarpıcı bir örnek, Berg'in tamamlanmış son eseri olan ve ancak ölümünden sonra seslendirilen 1935 tarihli Keman Konçertosu'dur. Berg konçertosunda aşağıdaki diziyi/seriyi kullanır:

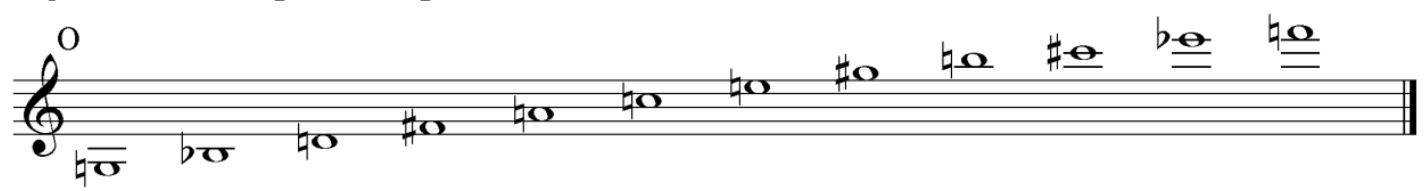

Örnek 8. Berg'in Keman Konçertosu'ndaki orijinal seri

(Example 8. Original serie in Berg's Violin Concerto)

Diziyi oluşturan aralıklara baktığımızda şöyle bir sıralanışın ortaya çıktığını görüyoruz: Küçük üçlü, büyük üçlü, büyük üçlü, küçük üçlü, küçük üçlü, büyük üçlü, büyük üçlü, küçük üçlü, büyük ikili, eksik üçlü, büyük ikili. Son aralık dışındaki aralıkların hepsi konsonans ve on bir kombinasyonun dokuzu üçlü aralıklardan oluşuyor. Bir başka bakış açısıyla ele alındığında ise bir minör triadı, majör bir triad, onu yine bir minör triad ve ardından yine bir majör triad izliyor. Bu 12 ton sisteminin mantığı içinde sıradışı bir dizilimdir. Çünkü 12 ton sisteminin esas felsefesi tonal çağırışımlardan ve eksen duygusundan kaçınmayı esas alır; bu sebeple de dizinin oluşumunda dissonans aralıklara ağırlık verir. Berg Keman Konçertosu'nda bu prensibin dışına çıkıyor ve geleneksel tonaliteyi çağırıştıran bir aralık dizilimine yer veriyor. Dizinin bu şekilde oluşturulması armonik yapının da çok daha tonal duyulmasıyla sonuçlanıyor. Birinci bölümün A temasının girişindeki (11. ve 14. ölçüler) akorlar piyanoya indirgeyerek aşağıdaki gibi örneklenebilir (Berg, 1936:3): 


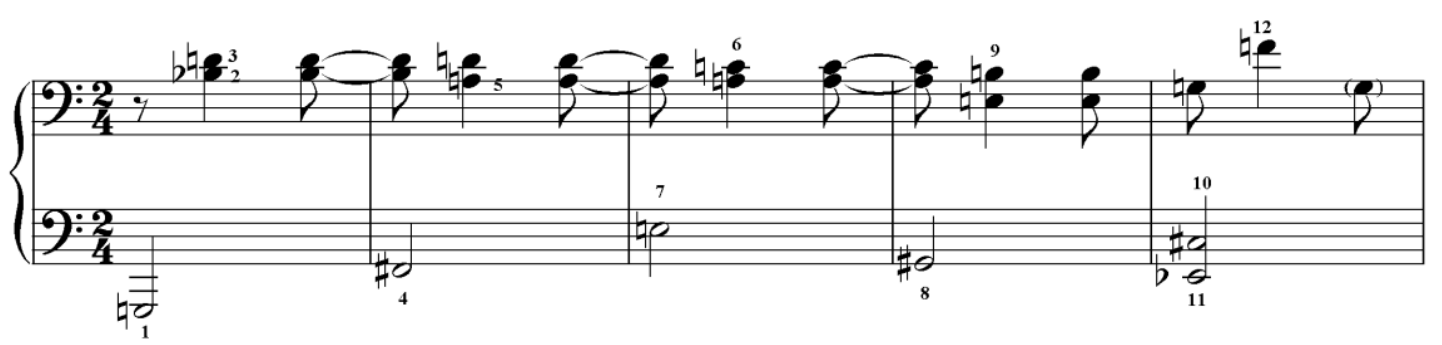

Örnek 9. Berg'in Keman Konçertosu'ndaki A Temasının armonik yapısı

(Example 9. Harmonic structre of Theme A in Berg's Violin Concerto)

Görüldüğü gibi akorlar dizinin orijinal notalarından oluşuyor. Fakat genel bir bakışta bile tonal bir analiz mümkün: Sol minörün I. derecesi, ardından dominant akoru, 3. ölçüde de la minörün I. derecesinin ikinci çevrimi, hemen sonra dominantı. Böylelikle on dokuzuncu yüzyılın armonik diline Schoenberg ya da Webern'in 12 ton yapıtlarından çok daha yakın bir duyuş sağlanmış oluyor. Hemen ardından dizi solo kemanda direkt bir biçimde tema olarak sunulur (Berg, 1936:4).

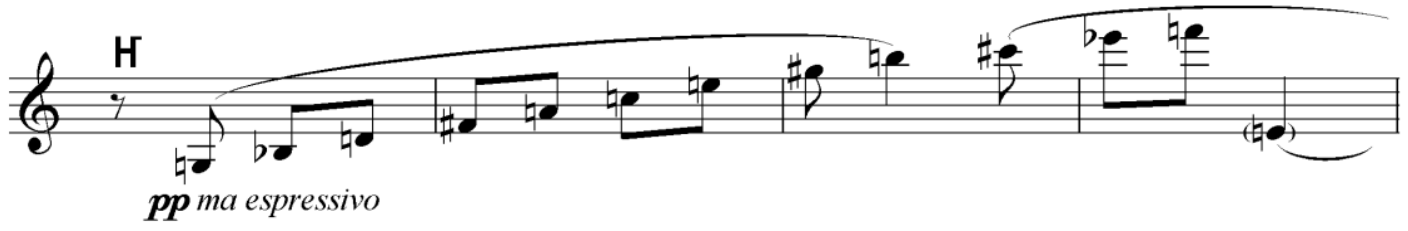

Örnek 10. Orijinal serinin solo kemanda kullanımı

(Example 10. Usage of the original serie in the solo violin)

Berg eserde 12 ton yazısının dışına da çıkarak J.S. Bach'ın "Es ist genug" adlı koralinden ve bir Karinthia halk şarkısından alıntılar yapar. Bu kolajlar on sekiz yaşında ölmüş Manon Gropius'a "Bir Meleğin Anısına" sözleriyle adanmış esere nostaljik bir belirsizlik duygusu katar.

\section{BULGULAR VE TARTIŞMA (FINDINGS AND DISCUSSIONS)}

12 ton tekniğinin kullanımını incelemek üzere, Scheonberg, Webern ve Berg'in birbirlerine çok yakın tarihlerde besteledikleri eserler seçilmiştir. Böylelikle dönemsel farklara değil, bestecilerin bu tekniği kullanışlarındaki kişisel benzerlik ve zıtlıklara odaklanmak mümkün olmuştur. Yapılan analizler sonucunda Schoenberg'le, başlıca öğrencileri Webern ve Berg'in 12 ton sistemini birbirlerinden oldukça farklı bir biçimde kullandıkları tespit edilmiştir. Üç besteci de aynı teknikten yola çıkarak bambaşka müzik dilleri yaratmışlardır. Schoenberg'in 12 ton sistemini kullanış tematiktir, tekstürel olarak on dokuzuncu yüzyıl geleneğini sürdürmektedir, form anlayışı oldukça klasiktir. Webern, 12 tonu tematik olarak kullanmaz, yazısı noktasalıık içerir, tını odaklıdır. Müziği form açısından kısa ve ekonomiktir. Simetrik dizilere eğilim gösterir. Berg 12 tonu daha serbest, tonal çă̆ırışımlara açık bir biçimde kullanır. Bu sebeple içlerinde Romantizme en yakın olanıdır. Yazısı tekstürel açıdan Webern'in aksine çok daha kitlesel ve yoğundur. Aşağıdaki tabloda bu bulgular özetlenmiştir. 
Tablo 1. Schoenberg, Webern Ve Berg'in 12 ton tekniği kullanımlarının

Table 1. Comparision of Schoenberg's, Webern's and Berg's 12 tone application techniques)

\begin{tabular}{|c|c|c|}
\hline Schoenberg & Webern & Berg \\
\hline $\begin{array}{c}\text { Diziyi/Seriyi } \\
\text { Tematik Olarak } \\
\text { Kullanır }\end{array}$ & $\begin{array}{c}\text { Diziyi Tematik Olarak } \\
\text { Kullanmaz. Simetrik } \\
\text { Kuruluşları Sever }\end{array}$ & $\begin{array}{c}\text { Diziyi Tematik Olarak } \\
\text { Kullanır. Tonal }\end{array}$ \\
\hline $\begin{array}{c}\text { Hem Kısa Hem Uzun } \\
\text { Formlara Yer Verir }\end{array}$ & Kısa Formları Tercih Eder & $\begin{array}{c}\text { Hem Kısa Hem Uzun Formlara } \\
\text { Yerse De Uzun Formlara } \\
\text { Daha Yatkındır }\end{array}$ \\
$\begin{array}{c}\text { Tekstürel Olarak On } \\
\text { Dokuzuncu Yüzyıl } \\
\text { Geleneğinden } \\
\text { Kopmamıştır }\end{array}$ & $\begin{array}{c}\text { Noktacı, Yenilikģi Bir } \\
\text { Tekstür. Suslar Da Notalar } \\
\text { Kadar Önem Kazanır }\end{array}$ & $\begin{array}{c}\text { Yoğun Bir Tekstür. Daha } \\
\text { Kabalık Bir Orkestrasyon }\end{array}$ \\
$\begin{array}{c}\text { Yapısalcı Yaklaşım } \\
\text { Bütünlük ve Tutarlılık } \\
\text { Gözetir }\end{array}$ & $\begin{array}{c}\text { Kolajlara Yer Verir. } \\
\text { Romantik Hayal Gücünü } \\
\text { Devreye Sokar }\end{array}$ \\
\hline
\end{tabular}

Üç bestecinin 12 ton kullanımları incelendiğinde Berg'in on dokuzuncu yüzyıl romantizmine daha yakın, Webern'in ise daha yenilikçi olduğu söylenebilir. Schoenberg stilistik açıdan iki öğrencisinin ortasında yer almaktadır. Sistemi bulan Schoenberg olmakla birlikte, Webern'in sonraki besteciler için daha öncü bir rol taşımasının sebebi, müziği tematiklikten uzaklaştırması ve tekstürel anlamda gelenekten ayrılmasıdır.

\section{SONUÇ VE ÖNERILLER (CONCLUSION AND RECOMMENDATIONS)}

Schoenberg'e göre müziksel yaratıcılık, bestecinin hissettiği bir kendini ifade etme ihtiyacından kaynaklanır. Kontrpuan ve armoni öğretimine de büyük önem vermekle beraber, onun için bu konudaki asıl bilgi, eski ustaların yapıtlarının incelenmesinden gelir. Bu sebeple besteci kendi dilini bulma sürecinde eski bestecilerin incelenmesine özellikle önem vermelidir. Webern'in ve Berg'in müzik dillerinin öğretmenlerinden bu kadar farklı ve bireysel olabilmesinin sebeplerinden biri de Schoenberg'in yaratıcılığı ön plana alan, esnek kompozisyon öğretimidir. Gerekli teknik bilgiyi vermiş, ama öğrencilerinin müzik diline karışmamıştır. Schoenberg ve öğrencilerinin, aynı teknikten yola çıkarak müziksel alanda bambaşka zenginlikler ortaya koymalarında, Schoenberg'in pedagojik başarısı büyüktür. 12 ton sistemini ortaya koyarak, müzik tarihinde yeni bir sayfa açan Schoenberg, kompozisyon öğretmeninin, öğrencisine bir stil empoze etmesine karşıdır. Forma önem vermekle birlikte, belli bir formda doldurmaca müzik yazılmasına da sıcak bakmaz. Hazır formüller değil, yaratıcı çözümleri önerir. Bir otodidakt olarak hem besteci hem de öğretmen olarak başarısında da müzik tekniğindeki araştırmacı ve metodik yaklaşımının büyük rolü vardır. Bu bağlamda kompozisyon öğretimi konusundaki görüşleriyle Schoenberg, birçok çağdaşının ilerisinde olmanın yanı sıra, günümüze de ışık tutmaktadır. Schoenberg örneğinden hareketle, kompozisyon öğretmeninin, teknik açıdan öğretici, düşünsel olarak yeniliklere açık olması, ama herhangi bir teknik, stil ya da akımı dayatmaktan da kaçınması gerektiği söylenebilir.

\section{SEMBOLLER-KISALTMALAR (SYMBOLS-ABBREVIATIONS)}

O: Original. Dizinin orijinal formu.

I: Inversion. Dizinin çevrimi.

R: Retrograde. Dizinin sondan başa yazımı.

RI: Retrograde-Inversion. Dizinin çevriminin sondan başa yazımı. 


\section{KAYNAKLAR (REFERENCES)}

- Berg, A., (1936). Violinkonzert, Wien: Universal Edition.

- Burkholder, J.P., Grout, D.J., and Palisca, C.V., (2006). A History of Western Music (seventh edition), New York: W.W. Norton \& Company.

- Dallin, L., (1974). Techniques of Twentieth Century Composition, Dubuque: WM. C. Brown Company Publishers.

- Encyclopædia Britannica, (1994). Chicago: Encyclopædia Britannica, Inc.

- Haimo, E., (1990). Schoenberg's Serial Odyssey, Oxford: Clarendon Press.

- Hayes, M., (1995). Anton von Webern, London: Phaidon Press Limited.

- Jarman, D., (1989). The Berg Companion, Boston: Northeastern University Press.

- Leibowitz, R., (1975). Schoenberg and His School, (Dika Newlin, Çev.), New York: Da Capo Press.

- Lester, J., (1989). Analytic Approaches to Twentieth-Century Music, New York: W.W. Norton \& Company.

- Lichtenfeld, M., (2001). Hauer, Josef Matthias. The New Grove Dictionary of Music and Musicians. Edited by Stanley Sadie and J. Tyrrell. London: Macmillan.

- MacDonald, M., (1987). Schoenberg, London: J.M. Dent \& Sons Ltd.

- Neighbour, O., (1988). Schoenberg in The New Grove Second Vienese School, London: Macmillan Publishers Limited.

- Neighbour, O.W., (2001). Schoenberg, Arnold. The New Grove Dictionary of Music and Musicians. Edited by Stanley Sadie and J. Tyrrell. London: Macmillan.

- Pamir, L., (1989). Müzikte Geniş Soluklar, İstanbul: Ada Yayınları.

- Schoenberg, A., (1936). Fourth String Quartet, New York: G. Schirmer, Inc.

- Schoenberg, A., (1970). Fundementals of Musical Composition, London: Faber and Faber.

- Stuckenschmidt, H.H., (1977). Schoenberg-His Life, World and Work, (Humphrey Searle, Çev.), London: John Calder.

- Reich, W., (1981). Schoenberg- a critical biography, New York: Da Capo Press.

- Webern, A., (1939). Streichquartett, London: Hawkes \& Son, Ltd. 